RESIDENT

\& FELLOW

SECTION

Section Editor

Mitchell S.V. Elkind,

MD, MS

Sashank Prasad, MD

Nicholas J. Volpe, MD

Madhura A. Tamhankar, $\mathrm{MD}$

Address correspondence and reprint requests to Dr. Sashank Prasad, Department of Neurology, Division of Neuroophthalmology, Hospital of the University of Pennsylvania, 3 Gates Bldg., 3400 Spruce St., Philadelphia, PA 19104

sashank.prasad@uphs.upenn.edu

\title{
Clinical Reasoning: A 36-year-old man with vertical diplopia
}

\section{SECTION 1}

A 36-year-old man with Von Hippel-Lindau syndrome presented with binocular vertical diplopia following suboccipital craniotomy for resection of a cerebellar hemangioblastoma. His diplopia was worse in left gaze. He was effectively treated with a 6-diopter base-down prism in the right eye. With-out spontaneous improvement after 10 months of using prisms, he desired an alternative to prism correction.

\section{Question for consideration:}

1. What features of the examination will help determine the cause of vertical diplopia? 
Table Examination techniques in the diagnosis of vertical diplopia

\begin{tabular}{|c|c|}
\hline Observation & Comment \\
\hline Head tilt or head turn & May be identified in prior photographs, indicating chronicity of strabismus and adaptation \\
\hline Ocular ductions & $\begin{array}{l}\text { Identify overt motility deficit, although ductions can often be normal in patients with ocular } \\
\text { vertical misalignment }\end{array}$ \\
\hline Forced ductions & Distinguish muscle restriction from paresis \\
\hline $\begin{array}{l}\text { Parks-Bielschowsky three-step } \\
\text { test }\end{array}$ & $\begin{array}{l}\text { Assessment of hypertropia in horizontal gaze and head tilt to identify the paretic } \\
\text { cyclovertical muscle }\end{array}$ \\
\hline Cover testing & $\begin{array}{l}\text { Identify misalignment (tropia) by covering the preferred eye and observing a movement of } \\
\text { redress in the fellow eye }\end{array}$ \\
\hline $\begin{array}{l}\text { Cover-uncover testing and } \\
\text { alternate cover testing }\end{array}$ & $\begin{array}{l}\text { Identify latent misalignment (phoria) by assessing movement of redress in the eye under } \\
\text { cover when cover is removed, after disrupted binocular fusion }\end{array}$ \\
\hline Maddox rod testing & Identify phoria for misalignment by preventing binocular fusion with disparate images \\
\hline Double Maddox rod testing & Identify relative cyclotorsion by presenting disparate images \\
\hline Dilated funduscopy & Identify cyclotorsion by direct visualization of position of macula with respect to optic disc \\
\hline Upright and supine testing & Assess any improvement of hypertropia or cyclotorsion in the supine position \\
\hline Fusional amplitude meas & Identify higher-order adaptive mechanisms for binocular fusion of disparate images \\
\hline
\end{tabular}

\section{SECTION 2}

A detailed neuro-ophthalmologic history and examination is critical for evaluation of double vision (table). First, it should be established whether double vision is monocular (persists with the fellow eye closed) or binocular (abates with one eye closed). Binocular diplopia results when misaligned eyes relay contradictory visuospatial information; it therefore does not occur when viewing through one eye only. Examination should include observation of abnormal posture, such as a head tilt or head turn that the patient may use to minimize symptoms; these may also be evident on old photographs. Ocular ductions (movements of each eye individually) and versions (movements of the eyes together) should be carefully examined in all directions, to identify abnormalities of muscle weakness or overaction. ${ }^{1}$ Weakness in a particular direction of gaze may be partial or complete, and may result from dysfunction at the level of the cranial nerve, eye muscle, or neuromuscular junction. Muscle overaction in a direction of gaze often signifies compensation for a long-standing or congenital process. The possibility of mechanical restriction (for example, from an orbital mass or extraocular muscle fibrosis) may be tested by evaluating forced ductions, using a cotton-tipped applicator or ophthalmic forceps to rotate the globe after applying topical anesthesia. In patients with nonrestrictive paresis, the eye can be moved the full extent of a normal duction.

It is common for patients with vertical misalignment to have no visible impairment in ocular motility. In this situation, cover testing is a useful technique to identify the ocular misalignment. While the subject fixates upon a target with both eyes, the examiner covers one eye and observes for a corrective saccade in the uncovered fellow eye. This correction, termed the movement of redress, occurs if the fellow eye is misaligned and refixates. Cover testing is repeated for the second eye, and is repeated in the nine cardinal positions of gaze. In this manner, an overt misalignment of the eyes will be identified as a hypertropia (relative elevation of one eye), exotropia (relative outward position of one eye), or esotropia (relative inward position of one eye). Variations of cover testing are the cover-uncover test and the alternate cover test, in which the movement of redress is observed in the eye under cover at the time the cover is removed. The period of monocular cover causes disruption of binocular vision, allowing a latent deviation (phoria) of the eyes to be detected. Detecting a latent deviation is critical because decompensation (for example, during periods of fatigue) is a common cause of intermittent binocular diplopia. To quantify a tropia or phoria in each direction of gaze, the methods of cover testing can be performed with prism held before one eye. The apex of the prism should point in the direction of the deviation (i.e., a basedown prism over the right eye would aid in quantifying a right hypertropia).

The Parks-Bielschowsky three-step test allows identification of the paretic cyclovertical muscle in patients with vertical misalignment. First, the hypertropic eye is identified; the paretic muscle must therefore be a depressor of one eye (inferior rectus or superior oblique) or an elevator of the other eye (superior rectus or inferior oblique). Second, it should be identified whether the hypertropia is worse in lateral gaze; hypertropia worse in contralateral gaze narrows the possibilities to weakness of the ipsilateral superior oblique or contralateral inferior rectus. 

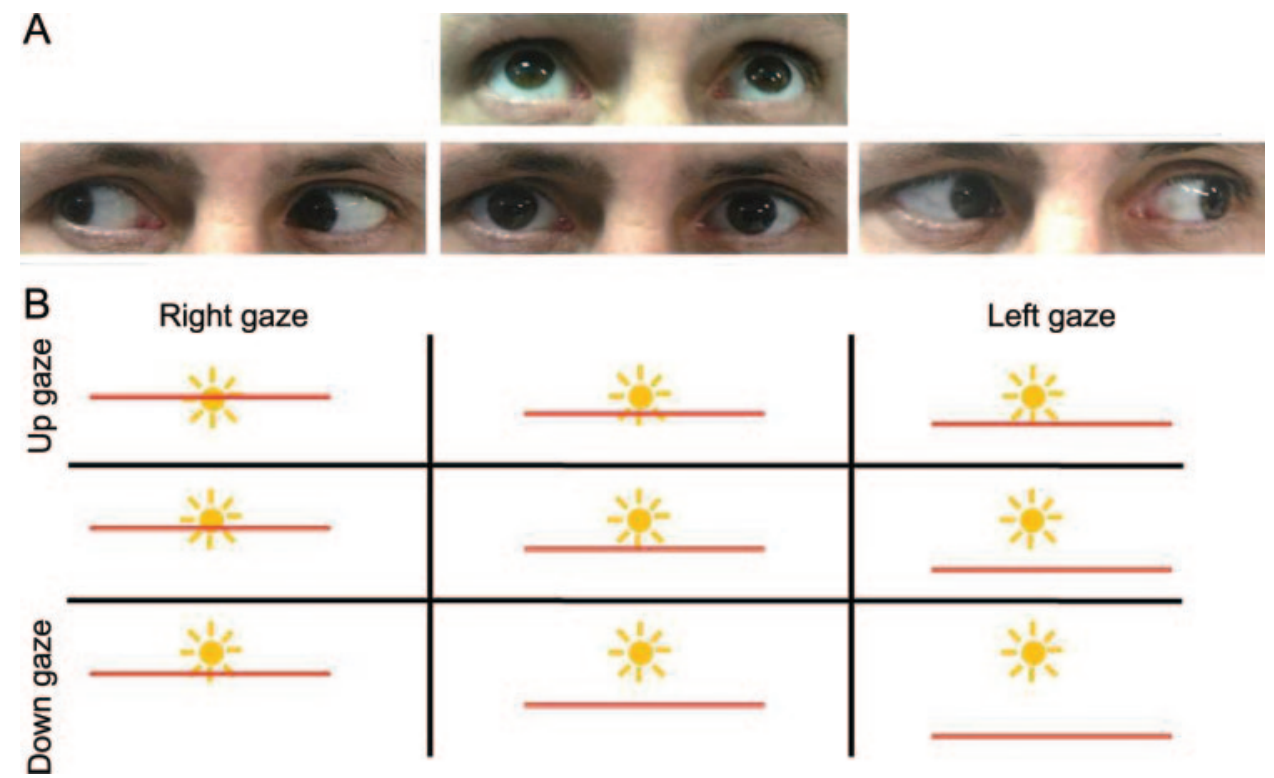

(A) Ocular motility. Note very small right hypertropia in primary gaze and upgaze, increased in left gaze. (B) Simulation of patient's view through Maddox rod in each direction of gaze. Note greatest vertical separation in down-and-left gaze.

Third, it should be identified if the hypertropia is worse with head tilt; hypertropia worse with ipsilateral head tilt must be due to weakness of either the ipsilateral intorter (superior oblique) or the contralateral extorter (inferior oblique). In cases where an isolated muscle is weak, application of these three rules allows the examiner to successfully identify the specific abnormality through a process of elimination. In some cases, however, the results of the three-step test may be misleading; these situations include chronic extraocular muscle paralysis or mechanical ocular muscle restriction (for example, due to an orbital floor fracture or thyroid eye disease).

Vertical misalignment of the eyes can also be evaluated with the Maddox rod, placed by convention over the right eye. This device prevents binocular fusion, because the viewer simultaneously sees disparate images (a point of light with the left eye and a red line with the right). If the eyes are misaligned, the red line does not intersect the point of light; it is displaced in the direction of weakness (opposite the direction of the deviation) because the image becomes projected onto extrafoveal retina (figure 1). The images are maximally separated during gaze in the direction of action of the paretic muscle. The Maddox rod provides a sensitive method to evaluate a small deviation or latent phoria that may not be evident on cover-uncover or alternate cover testing.

Torsional diplopia often accompanies vertical diplopia, resulting from ocular cyclotorsion. $\mathrm{Cy}$ clotorsion can be evaluated with the double Maddox rod or dilated funduscopy (by assessing the position of the macula with respect to the optic disc). Assessing cyclotorsional and vertical misalignment in both the upright and supine position may be helpful in distinguishing specific causes of vertical misalignment. ${ }^{2}$

The patient's ability to fuse disparate images (fusional amplitude) is an important clue in assessing the chronicity of vertical strabismus. With progressively increased prism placed over one eye, the patient is asked to report double vision. A vertical fusional capacity greater than $8-10$ diopters suggests the presence of higher compensatory mechanisms that occur with long-standing misalignment.

Differential diagnosis. Binocular vertical diplopia has a limited differential diagnosis, which includes third nerve palsy, fourth nerve palsy, skew deviation, extraocular muscle restriction (for example, thyroid eye disease), and neuromuscular junction impairment (for example, myasthenia gravis). In third nerve palsy and fourth nerve palsy, the amount of hyperdeviation of one eye is greatest in the direction of action of the affected muscle. This unequal amount of misalignment in each direction of gaze is termed incomitance. Skew deviation, on the other hand, is a cause of vertical alignment in which the amount of misalignment does not follow an incomitant pattern typical of third or fourth nerve palsy. In contrast to those conditions, the hyperdeviation in a skew may be fairly equal (comitant) in each direction of gaze. Skew deviation is thought to be caused by imbalanced utricular inputs from the inner ear, leading 
to a compensatory, reflexive cyclovertical ocular deviation.

On examination, the patient's ocular ductions were full, without evidence of inferior oblique overaction (figure 1). There was a very small right hypertropia, greatest in left gaze. Maddox rod testing confirmed a right hypertropia of 6-8 diopters in primary position, increasing in left gaze to 8-10 diopters, and increasing further in down-and-left gaze to 10-12 diopters (figure 1). The misalignment was significantly less in upgaze, measuring 4 diopters. On right head tilt, the deviation increased to 12 diopters, and on left head tilt it decreased to 4 diopters. Measurements taken in the supine position were not different from those in the vertical position. Cyclotorsion was not appreciated on funduscopy, but double Maddox rod testing revealed 5 degrees of relative excyclotorsion of the right eye. Except for mild dysarthria and gait ataxia, the remainder of the examination was normal.

\section{Question for consideration:}

1. What cause of vertical ocular misalignment does this examination confirm, and why? 


\section{SECTION 3}

The findings of right hypertropia greatest in contralateral gaze and ipsilateral head tilt suggest a right fourth nerve palsy. According to the ParksBielschowsky three-step test, right hypertropia suggests weakness of the right superior oblique, right inferior rectus, left inferior oblique, or left inferior rectus muscles. Next, increased right hypertropia in contralateral gaze narrows the possibilities to right superior oblique or left inferior rectus weakness. Finally, increased right hypertropia on ipsilateral head tilt further reduces the possibilities, ultimately identifying right superior oblique weakness.

The reason that superior oblique dysfunction causes this pattern of impaired motility relates to its mechanical properties. The superior oblique arises from the orbital apex, passes through a fibrocartilaginous trochlea just inside the superior medial orbital rim, and then inserts on the superior lateral aspect of the globe, posterior to the equator. Its main action, therefore, depends upon the position of the eye: when the eye is abducted, the superior oblique is a strong intorter, and when the eye is adducted, it is a depressor. Its tertiary action is abduction of the globe in depression.

The reason that hypertropia is exacerbated in contralateral gaze is that there is weakness of depression in adduction (or, in long-standing cases, the hypertropia is due to overaction of the ipsilateral inferior oblique, which further elevates the eye in adduction). The reason hypertropia is worse with ipsilateral head tilt is that the ocular counter-roll reflex stimulates ipsilateral intorters (superior oblique and superior rectus) and contralateral extorters (inferior oblique and inferior rectus); when the superior oblique is weak, this reflex causes compensatory increase in ipsilateral superior rectus action, resulting in additional hypertropia (since the superior rectus is an elevator). In skew deviation, head tilt does not worsen hypertropia, since these ocular counter-roll mechanisms are intact.

Additional findings that indicate fourth nerve palsy over skew deviation are excyclotorsion of the eye and persistence of hypertropia in the supine position. Excyclotorsion of the hypertropic eye suggests fourth nerve palsy, because of weakened intorsion; in contrast, intorsion of the hypertropic eye occurs in skew deviation, due to decreased stimulation of the inferior oblique subnucleus. The reason that hyperdeviation is mitigated in the supine position in skew deviation, but not fourth nerve palsy, relates to the fact that utricular inputs depend upon head position; the utricular imbalance that causes a skew deviation is lessened in the supine position, and the amount of ocular hyperdeviation is reduced. ${ }^{2}$

\section{Question for consideration:}

1. What is the differential diagnosis for a fourth nerve palsy and what testing would you pursue? 
Figure 2 Preoperative and postoperative gadolinium-enhanced T1-weighted MRI scans, demonstrating fourth ventricle hemangioblastoma

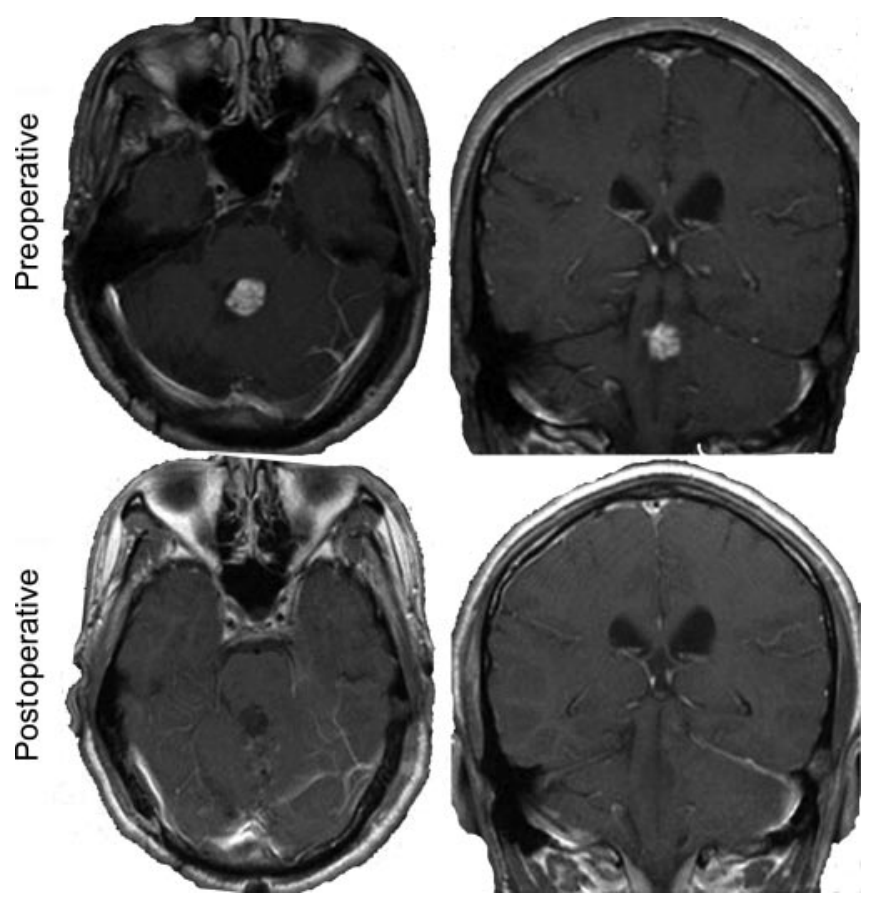

SECTION 4

In patients with a fourth nerve palsy, the etiology can often be determined by history and examination alone. Neuroimaging is required when the cause is unclear.

The most common cause of acquired fourth nerve palsy is trauma. The trochlear nerve is the longest and thinnest of all the cranial nerves, coursing along the free edge of the tentorium through the prepontine cistern, where it is vulnerable to crush injury. In cases of bilateral traumatic fourth nerve palsies, both nerves are often injured at the anterior medullary vellum, where they decussate. ${ }^{3}$
Decompensated congenital fourth nerve palsy is also common and may present in adulthood. Characteristic features of congenital fourth nerve palsy include head tilt, inferior oblique overaction, large vertical fusional amplitude, hypertropia greater in upgaze, and minimal torsional diplopia. The precise etiology of congenital fourth nerve palsy is unclear but may include hypoplasia of the nucleus, birth trauma, anomalous muscle insertion, muscle fibrosis or adhesion, or structural abnormalities of the tendon. ${ }^{4}$ The cause of decompensation is likely breakdown of vertical fusion that leads to symptomatic diplopia, rather than progressive superior oblique dysfunction. ${ }^{5}$

Ischemic fourth nerve palsy is less common, but occurs most often in patients over age 50 with vascular risk factors. There is often periorbital aching pain on presentation, and excellent spontaneous recovery is expected over several months.

Less frequent causes of fourth nerve palsy include midbrain hemorrhage or infarction, schwannoma, aneurysmal compression, meningitis, demyelination, giant cell arteritis, hydrocephalus, and herpes zoster ophthalmicus. Finally, when ancillary testing fails to support a definitive etiology, a diagnosis of idiopathic acquired fourth nerve palsy can be made.

In our patient, brain MRI revealed postoperative changes related to resection of a hemangioblastoma within the fourth ventricle. The etiology of his right fourth nerve palsy was most likely intraoperative trauma (figure 2).

\section{Question for consideration:}

1. How should a patient with a fourth nerve palsy be managed? 


\section{SECTION 5}

There are several treatment options for the patient with superior oblique palsy. Occlusion of the affected eye (or, if diplopia occurs only in down-andcontralateral gaze, occlusion of the lower half of the lens over the affected eye) can serve as a temporary measure, when spontaneous recovery is expected. Alternatively, base-down prism over the affected, hypertropic eye may alleviate diplopia (by shifting the image downward to the fovea). Temporary press-on Fresnel prisms may be tried before permanent prisms are ground into the lenses. The disadvantage of prisms is that the patient may have an unequal amount of misalignment in each direction of gaze (i.e., an incomitant deviation), yet the prism is only capable of providing a fixed amount of correction for misalignment. The patient may therefore continue to experience diplopia in eccentric gaze. Furthermore, torsional diplopia cannot be corrected by prisms.

Surgery may be necessary for persistent symptomatic fourth nerve palsy when conservative measures fail, as long as measurements of misalignment have been stable over several months. The general principle behind strabismus surgery is to detach and reattach the appropriate extraocular muscles in a position that achieves better ocular alignment, particularly in primary gaze. Patients with decompensated congenital fourth nerve palsy generally have a better progno- sis after surgery than patients with acquired fourth nerve palsy, because they often have increased vertical fusional amplitude that reduces the likelihood of postoperative diplopia. ${ }^{6}$

To improve ocular alignment, we performed a left inferior rectus weakening procedure. Postoperatively, the patient had 1 diopter right hypertropia in primary and eccentric gaze, measured by Maddox rod testing. Subjective vertical diplopia was successfully eliminated.

\section{REFERENCES}

1. Kushner BJ. Multiple mechanisms of extraocular muscle "overaction." Arch Ophthalmol 2006;124:680-688.

2. Parulekar MV, Dai S, Buncic JR, Wong AM. Head position-dependent changes in ocular torsion and vertical misalignment in skew deviation. Arch Ophthalmol 2008; 126:899-905

3. von Noorden GK, Murray E, Wong SY. Superior oblique paralysis: a review of 270 cases. Arch Ophthalmol 1986; 104:1771-1776.

4. Helveston EM, Krach D, Plager DA, Ellis FD. A new classification of superior oblique palsy based on congenital variations in the tendon. Ophthalmology 1992;99:16091615.

5. Mansour AM, Reinecke RD. Central trochlear palsy. Surv Ophthalmol 1986;30:279-297.

6. Maruo T, Iwashige H, Kubota N, et al. Long-term results of surgery for superior oblique palsy. Jpn J Ophthalmol 1996;40:235-238. 


\title{
Neurology
}

\author{
Clinical Reasoning: A 36-year-old man with vertical diplopia \\ Sashank Prasad, Nicholas J. Volpe and Madhura A. Tamhankar \\ Neurology 2009;72;e93-e99 \\ DOI 10.1212/WNL.0b013e3181a55ee3
}

This information is current as of May 11, 2009

\section{Updated Information \& Services}

References

Citations

Subspecialty Collections

Permissions \& Licensing

Reprints including high resolution figures, can be found at: http://n.neurology.org/content/72/19/e93.full

This article cites 6 articles, 0 of which you can access for free at: http://n.neurology.org/content/72/19/e93.full\#ref-list-1

This article has been cited by 1 HighWire-hosted articles: http://n.neurology.org/content/72/19/e93.full\#\#otherarticles

This article, along with others on similar topics, appears in the following collection(s):

Clinical neurology examination

http://n.neurology.org/cgi/collection/clinical_neurology_examination Clinical neurology history

http://n.neurology.org/cgi/collection/clinical_neurology_history

Diplopia (double vision)

http://n.neurology.org/cgi/collection/diplopia_double_vision

Ocular motility

http://n.neurology.org/cgi/collection/ocular_motility

Information about reproducing this article in parts (figures,tables) or in its entirety can be found online at:

http://www.neurology.org/about/about_the_journal\#permissions

Information about ordering reprints can be found online:

http://n.neurology.org/subscribers/advertise

Neurology ${ }^{\circledR}$ is the official journal of the American Academy of Neurology. Published continuously since 1951, it is now a weekly with 48 issues per year. Copyright. All rights reserved. Print ISSN: 0028-3878. Online ISSN: 1526-632X.

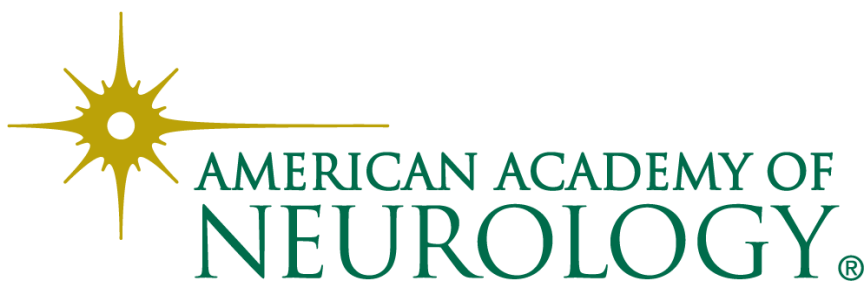

